\title{
Identification of expanded T-cell clones by spectratyping in nonfunctioning kidney transplants
}

This article was published in the following Dove Press journal:

Journal of Inflammation Research

3 May 2017

Number of times this article has been viewed

\author{
Maria Cappuccilli' \\ Gabriele Donati' \\ Giorgia Comai' \\ Olga Baraldi' \\ Diletta Conte' \\ Irene Capelli' \\ Valeria Aiello' \\ Andrea Pession ${ }^{2}$ \\ Gaetano La Manna' \\ 'Department of Experimental \\ Diagnostic and Specialty Medicine \\ (DIMES), Nephrology, Dialysis, \\ and Renal Transplant Unit, \\ ${ }^{2}$ Molecular Laboratory of Pediatrics, \\ Hematology-Oncology Unit, St \\ Orsola Hospital, University of \\ Bologna, Bologna, Italy
}

Background: The aim of this study was the application of complementarity-determining region-3 spectratyping analysis to determine T-cell-repertoire complexity and to detect T-cellclone expansion, as a measure of immune response in nonfunctioning kidney transplants (group hemodialysis-transplant [HD-Tx]), nontransplanted dialysis patients (group hemodialysis [HD]), and normal subjects as controls (group C).

Patients and methods: Analysis of T-cell receptor (TCR) diversity by spectratyping was applied to peripheral blood samples collected from 21 subjects: eight in group HD-Tx, seven in group HD, and six in group C.

Results: Considering the extent of the skew in TCR variable region repertoires as a measure of clonal $\mathrm{T}$ cells, we found that the number of altered spectra showed a progressive increase from normal subjects to dialysis patients and to nonfunctioning kidney transplants, respectively. Healthy subjects had the lowest number of altered spectra, and patients with nonfunctioning kidney transplants the highest. Differences were significant for group HD-Tx vs group $\mathrm{C}(P=0.017)$ and group $\mathrm{HD}$ vs group $\mathrm{C}(P=0.015)$, but not between nonfunctioning kidney-transplant recipients and dialysis patients (group HD-Tx vs group HD).

Conclusion: Although dialysis appears to be a weaker trigger for clonal expansion of $\mathrm{T}$ cells, our data suggest that the utilization of complementarity-determining region-3 spectratyping analysis of the TCR repertoire might be useful to monitor specific immunoactivation in patients before and after kidney transplantation.

Keywords: dialysis, nonfunctioning kidney transplant, T-cell repertoire, TCR spectratyping

\section{Introduction}

Kidney transplantation is considered the treatment of choice for patients with endstage renal disease, since it restores patients' quality of life and reduces morbidity and mortality rates associated with dialysis. ${ }^{1,2}$ The introduction of new immunosuppressant drugs has greatly decreased the number and impact of acute rejections, which however is still a critical complication. ${ }^{3,4}$ Unfortunately, several pathological changes due to immunological and nonimmunological components for organ loss lead to a progressive loss of graft function, and this condition does not seem to have received consistent benefits from the new pharmacological treatments. ${ }^{5,6}$ The main consequence is the necessity to retransplant patients who are often sensitized or highly sensitized by a previous transplant, with a resulting higher percentage of patients in transplantwaiting lists needing a second transplantation, longer average waiting times, and a further increase in the gap between organ demand and availability. ${ }^{7-9}$ There is much evidence suggesting how immunosuppressive therapy remains too aspecific a strategy
Correspondence: Gaetano La Manna Department of Experimental, Diagnostic and Specialty Medicine (DIMES), Nephrology, Dialysis and Renal Transplant Unit, St Orsola Hospital, University of Bologna, 9 Via Giuseppe Massarenti - Pad 15, Bologna 40138, Italy Tel +390512144577

Fax +39 05I 344439

Email gaetano.lamanna@unibo.it 
to improve graft survival, and additionally it is not practicable to stress systemic immunosuppression, owing to the related possible complications, mainly viral infections, malignancy, nephrotoxicity, and cardiovascular disease. ${ }^{10-14}$

Growing attention is currently focused on the development and protective mechanisms of graft tolerance, in which T-cell responses in both innate and adaptive immunity play a major role. ${ }^{15}$ Accumulating evidence suggests that innate immunity interacts with the adaptive immune system to identify antigens and eliminate them from the host. ${ }^{16}$ Both components are implicated not only in acute rejection but also in chronic allograft nephropathy, which in turn is related to immune and nonimmune mechanisms, including the activation of $\mathrm{CD}^{+} \mathrm{T}$ cells. ${ }^{5,6,10,17} \mathrm{~T}$-cell recognition of the antigen is mediated by the T-cell receptor (TCR), composed of $\alpha$ - and $\beta$-chains, each composed of a variable (V) gene segment, a joining ( $\mathrm{J}$ ) segment, and a constant $(\mathrm{C})$ region. The $\beta$-chains have a diversity (D) gene segment between the $\mathrm{V}$ and $\mathrm{J}$ segments. During T-cell development, one V, one D, and one $\mathrm{J}$ gene segment are randomly rearranged, resulting in more than 1,000 possible junctional combinations of $\alpha$ - and $\beta$-chains. ${ }^{18}$ The specificity of antigen recognition is mainly due to the presence of the complementarity-determining region-3 (CDR3), a junctional region between the $\mathrm{V}, \mathrm{D}$, and $\mathrm{J}$ gene segments..$^{19,20}$ The possibility to characterize the specific T-cell repertoires may have considerable repercussions on many areas of interest, including autoimmunity, response to superantigens, tumor immunity, and immunoreconstitution after bone marrow and solid-organ transplantation. Since the hypervariable TCR region is related to the clonal expansion of $\mathrm{T}$ cells against specific antigens, the early identification of these clones via TCR-diversity analysis might provide a valid tool to monitor their progression and to delineate specific treatments. ${ }^{21-26}$

Spectratyping is a method able to evaluate T-cell-repertoire complexity through CDR3-size heterogeneity of the TCR $\beta$-chain, and represents a more powerful approach than lymphocyte-subset analysis through flow cytometry, for the clinical immunomonitoring of solid-organ recipients. ${ }^{25-27}$ The CDR3 sequence defines a unique clonotype that behaves as a fingerprint for the T-cell line bearing it. The study of TCR repertoires using length analysis of CDR3 hypervariable regions could concur to follow the immunological status of each patient and to identify early expansion of T-cell clones involved in immune response, thus providing the necessary steps for clone-specific therapeutic strategies. ${ }^{22,23}$

In this study on a limited number of subjects, we investigated the application of spectratyping for the identification of T-cell-clone expansion after renal transplantation. In order to investigate the immune response in patients with a nonfunctioning graft compared to those under chronic dialysis treatment with no previous kidney transplant, we evaluated the differences in the number of altered spectra in peripheral blood samples in three groups of patients: nonfunctioning kidney-transplant recipients vs nontransplanted dialysis patients vs healthy control subjects.

\section{Patients and methods}

\section{Patients}

A total of 21 subjects were enrolled in the study and assigned to three groups: the first composed of eight nonfunctioning kidney-transplant recipients under dialysis treatment, negative for the presence of preformed human leukocyte antigen (HLA) antibodies (group hemodialysis-transplant [HD-Tx]); the second group consisted of seven dialysis patients with no previous renal transplant (group hemodialysis [HD]); and the third included six healthy subjects with normal renal function, used as the control group (group C). Patients in groups HD-Tx and HD were on regular bicarbonate hemodialysis therapy three times a week at our dialysis center.

Inclusion criteria were age above 18 years, and for dialysis patients in groups HD-Tx and HD: 1) clinical stability of at least 3 months before study entry; 2) functioning arteriovenous fistula as vascular access; and 3) absence of active gastrointestinal bleeding, diabetes, amyloidosis, focal segmental glomerulosclerosis, autoimmune diseases, vasculitis, and malignancy. As shown in Table 1, the subjects included in each group were matched for general parameters (sex distribution and age). Groups HD-Tx and HD were comparable for dialysis vintage, chronic kidney-disease duration, and serum creatinine. Causes of transplant failure in the HD-Tx group were biopsy-proven chronic allograft nonimmune injury (interstitial fibrosis and tubular atrophy) in five patients, recurrent primary disease in two patients, and de novo disease in one patient.

To exclude interference due to anti-HLA antibody production in patients with nonfunctioning kidney transplants, all subjects in group HD-Tx were assayed for posttransplant HLA-specific IgG antibodies through enzyme-linked immunosorbent assay panel-reactive antibodies), as previously described by Costa et al. ${ }^{28}$ Therefore, patients in group HD-Tx were selected only if they tested negative for specific HLA antibodies in three consecutive controls. All patients in HD-Tx group had been tapered from immunosuppression to low-dose monotherapy steroids ( $5 \mathrm{mg}$ /day prednisone). Dialysis patients with no previous transplant (group HD) were always negative for panel-reactive antibodies and HLA specificity. 
Table I Demographic, clinical, and biochemical parameters of the study groups

\begin{tabular}{|c|c|c|c|c|c|}
\hline Parameter & $\begin{array}{l}\text { A } \\
\text { HD-Tx }(n=8)\end{array}$ & $\begin{array}{l}\text { B } \\
\text { HD }(n=7)\end{array}$ & $\begin{array}{l}\text { C } \\
\text { Healthy }(n=6)\end{array}$ & P (Kruskal-Wallis) & $\begin{array}{l}\text { Post hoc } \\
\text { comparisons }\end{array}$ \\
\hline Sex (male/female) & $4 / 4$ & $4 / 3$ & $3 / 3$ & NS & - \\
\hline Age (years) & $47.9 \pm 8.6$ & $48.3 \pm 6.3$ & $47.1 \pm 7.9$ & NS & - \\
\hline Dialysis vintage (months) & $50.1 \pm 22.3$ & $51.1 \pm 20$ & - & NS & - \\
\hline CKD duration (months) & $64.5 \pm 65.1$ & $75.6 \pm 83$ & - & NS & - \\
\hline Serum creatinine $(\mathrm{mg} / \mathrm{dL})$ & $9.1 \pm 3.6$ & $9.8 \pm 3$ & $0.9 \pm 0.2$ & $<0.001$ & $\mathrm{~A}, \mathrm{~B}<\mathrm{C}$ \\
\hline Primary disease & & & & & - \\
\hline Glomerulonephritis & 1 & 2 & - & & \\
\hline Polycystic kidney disease & 2 & I & - & & \\
\hline Interstitial nephritis & I & I & - & & \\
\hline Vascular nephropathy & 3 & 2 & - & & \\
\hline Hereditary nephropathy & 0 & 0 & - & & \\
\hline Not diagnosed & I & I & - & & \\
\hline
\end{tabular}

Notes: Categorical variables presented as percentages, and continuous variables presented as mean \pm standard deviation. Differences between the groups were computed using Kruskal-Wallis analysis of variance followed by Mann-Whitney $U$ tests for post hoc comparison.

Abbreviations: CKD, chronic kidney disease; NS, not significant; HD-Tx, hemodialysis-transplant; HD, hemodialysis.

The study was carried out in conformity with the Declaration of Helsinki. Written informed consent was obtained before inclusion from all subjects, and the protocol was approved by the ethical committee of St OrsolaMalpighi University Hospital, Bologna, Italy (protocol BO-SO_NEPH2011_07).

\section{RNA extraction and reverse- transcription reaction}

Peripheral blood mononuclear cells were isolated from heparinized blood by Isopaque Ficoll (Lymphoprep; Nycomed, Zurich, Switzerland) gradient centrifugation, then total RNA was extracted with an RNeasy minikit (Qiagen NV, Venlo, the Netherlands) according to the manufacturer's instructions. For each sample, $1 \mu \mathrm{g}$ of RNA was reversetranscribed to complementary DNA using random hexanucleotide primers and reverse transcriptase (Superscript; Thermo Fisher Scientific, Waltham, MA, USA), with a thermal profile of 10 minutes $25^{\circ} \mathrm{C}, 60$ minutes $42^{\circ} \mathrm{C}$, and 5 minutes $99^{\circ} \mathrm{C}$.

\section{Polymerase chain reaction}

The TCR $\mathrm{V}_{\beta}$ gene subfamilies were amplified by a constant primer labeled at the 5' terminus with the dye FAM (6-carboxyfluorescein), coupled with other specific primers, first designed by Gorski et al. ${ }^{21}$ Briefly, $20 \mu \mathrm{L}$ aliquots of working solution containing GeneAmp ${ }^{\circledR}$ polymerase chainreaction (PCR; Thermo Fisher Scientific), $2 \mathrm{mM} \mathrm{MgCl}$, $0.2 \mathrm{mM}$ of each deoxyribonucleotide triphosphate, $0.1 \mathrm{mM}$ of each primer, and $1 \mu \mathrm{L}$ of complementary DNA were amplified with the following PCR conditions: denaturation
30 seconds $95^{\circ} \mathrm{C}$, annealing 30 seconds $58^{\circ} \mathrm{C}$, extension 45 seconds $72^{\circ} \mathrm{C}, 29$ cycles; final extension 5 minutes $72^{\circ} \mathrm{C}$. An aliquot of $5 \mu \mathrm{L}$ of the final PCR product was analyzed by electrophoresis in a $2 \%$ agarose gel (FMC, Rockland, ME, USA) with $0.5 \mu \mathrm{g} / \mathrm{mL}$ of ethidium bromide in $0.5 \times$ Tris-borate-ethylenediaminetetraacetic acid buffer (Thermo Fisher Scientific), and then visualized under an ultraviolet transilluminator.

\section{T-cell spectratyping}

PCR product $(1 \mu \mathrm{L})$ was denatured in $15 \mu \mathrm{L}$ formamide and electrophoresed through POP- $4^{\circledR}$ on an ABI 310 automated sequencer in the presence of Tamra 400HD ROX size standard (all Thermo Fisher Scientific). As a result of TCR $\beta$-chain rearrangements, each amplification shows a certain pattern of bands related to the complexity of the T-cell repertoire and the concentration of one or few expanded clones species within the size class. Spectratyping analysis was performed in duplicate for the $\mathrm{V}_{\beta}$ families $\mathrm{V}_{\beta 2}, \mathrm{~V}_{\beta 4}, \mathrm{~V}_{\beta 5.1}$, $\mathrm{V}_{\beta 5.3}, \mathrm{~V}_{\beta 7}, \mathrm{~V}_{\beta 9}, \mathrm{~V}_{\beta 12}, \mathrm{~V}_{\beta 13}, \mathrm{~V}_{\beta 14}, \mathrm{~V}_{\beta 15}, \mathrm{~V}_{\beta 16}, \mathrm{~V}_{\beta 17}, \mathrm{~V}_{\beta 19}, \mathrm{~V}_{\beta 21}, \mathrm{~V}_{\beta 23}$, and $\mathrm{V}_{\beta 24}$. GeneScan and Genotyper 2.1 softwares (Thermo Fisher Scientific) were used to classify each $V_{\beta}$ histogram peak by its PCR-size length and compute the area under curve (AUC) of each peak.

Normally, in healthy subjects, the CDR3-length distributions of each TCR $\mathrm{V}_{\beta}$ family contain at least six peaks in a Gaussian distribution, suggestive of a polyclonal T-cell expansion. Any perturbation in TCR $\mathrm{V}_{\beta}$ CDR3 repertoire, referred to as "skewing", results in a markedly non-Gaussian CDR3-length distribution, suggesting a clonal or oligoclonal T-cell population. Specifically, we considered as skewed any 
TCR $V_{\beta}$ family exhibiting a predominant peak, defined by an AUC within a given CDR3 spectratype of greater than $40 \%$ of the sum of the total AUC.

\section{Statistical analysis}

Continuous variables are presented as mean \pm standard deviation and categorical variables as number and percentage. Differences between groups were computed using KruskalWallis analyses of variance followed by Mann-Whitney $U$ tests. $P$-values below 0.05 were considered significant, and all statistical analyses were performed using Statistical Package for the Social Sciences (SPSS) for Windows version 16.0.

\section{Results}

All the subjects participating in the study presented skewed spectra, including those in the control group. The technique showed high specificity and repeatability. The number of altered spectra revealed no correlation with sex, age, or dialysis vintage. Qualitative evaluation of skewed spectra revealed high variability in the three groups, although the number of patients was too small to provide statistically significant correlations of specific altered $\mathrm{V}_{\beta}$-chain $\mathrm{CDR} 3$ regions with clinical outcomes. Figure 1 shows the complete spectra patterns for patients in each group who presented an intermediate number of alterations.

To determine the number of skewed spectra for each patient in the three groups, we observed electropherograms of TCR $V_{\beta}$ amplicons and expressed the "area under the peak" as the quantity of labeled $V_{\beta}$-fragment PCR product of a defined length measured by the detector. From the evaluation of the amount of altered spectra in each group, we applied Kruskal-Wallis analyses of variance, followed by Mann-Whitney $U$ tests to compare the AUC for each peak of all $\mathrm{V}_{\beta}$ families across the three groups. Table S1 shows the AUC of each peak for all $\mathrm{V}_{\beta}$ families analyzed for each subject in the three groups: HD-Tx $(n=8)$ vs HD $(n=7)$ vs $C(n=6)$.

As Table 2 shows, there was a progressive increase in the number of skewed spectra from healthy subjects to dialysis patients and to nonfunctioning kidney transplants, respectively. When each $V_{\beta}$ family was considered separately, no significant differences were found among the three groups, but the differences were significant for the sum of total skewed spectra $(P<0.001)$.

Healthy subjects had the fewest altered spectra and patients with a nonfunctioning kidney transplant the highest. Applying post hoc Mann-Whitney nonparametric tests, we found that differences were significant for group HD-Tx vs group $\mathrm{C}(P=0.017)$ and group $\mathrm{HD}$ vs group $\mathrm{C}(P=0.015)$, but not for nonfunctioning kidney-transplant recipients vs dialysis patients (group HD-Tx vs group HD).

\section{Discussion}

The possibility of identifying oligoclonal T-cell expansions of TCR $V_{\beta}$ families in kidney transplants can represent a fascinating research field in kidney-transplant tolerance. The analysis of TCR diversity through spectratyping in our patients suggested that renal transplant recipients who experienced graft failure were characterized by more persistent expanded T-cell clones, with a potential specific role in the acceptance of transplanted solid organs. ${ }^{27,29}$ Previous evidence has indicated that the extent of skewing of TCR repertoires and levels of clonal T-cell expansion are significantly correlated with renal transplant outcomes. It has been reported that a decrease in the number of donor-reactive T-cell clones is more directly associated with tolerance induction, whereas allograft rejection can trigger clonal expansion of T cells. ${ }^{30,31}$

In our study, we selected a limited number of renal transplant recipients with a nonfunctioning graft negative for donor-specific antibodies to avoid the introduction of a further confounding variable. The eight-patient HD-Tx group had lost graft function, due to nonimmune injury (interstitial fibrosis/tubular atrophy) previously diagnosed by renal biopsy in five, recurrent primary disease in two, and de novo disease in one. The group of renal transplant recipients with a nonfunctioning graft showed the maximum number of skewed spectra, although the difference from dialysis patients did not reach statistical significance. It is feasible that previous cell-mediated acute and/or chronic reactions might have elicited persistent specific HLA-sensitization responsiveness, leading to allograft intolerance. On the other hand, the limited number of patients prevented us from applying other statistical analyses or to draw any firm conclusion about the real influence of dialysis on T-cell-clone expansion. The higher extent of skewing in patients with a failed graft seems to indicate a link between altered $\mathrm{V}_{\beta}$-chain $\mathrm{CDR} 3$ regions and immunological response against HLAs.

In spite of the small sample size and differences in the patient population, these findings show a certain consistency with a recent report by Morris et al, who described a drop in donor-reactive T-cell clones in tolerant combined kidney and bone marrow-transplant recipients. The same reductions were not observed in intolerant patients or standard renal transplant patients treated with standard immunosuppressive regimens. T-cell-repertoire turnover due to lymphocyte-depleting conditioning only partially accounted for the observed reductions in tolerant patients, supporting the hypothesis that one key mechanism of allograft-tolerance induction may be T-cellclonal deletion. ${ }^{31}$

The actual difficulty is related to the apparent variability of the spectra-alteration pattern detected in each group 
Group HD-Tx

Patient 2

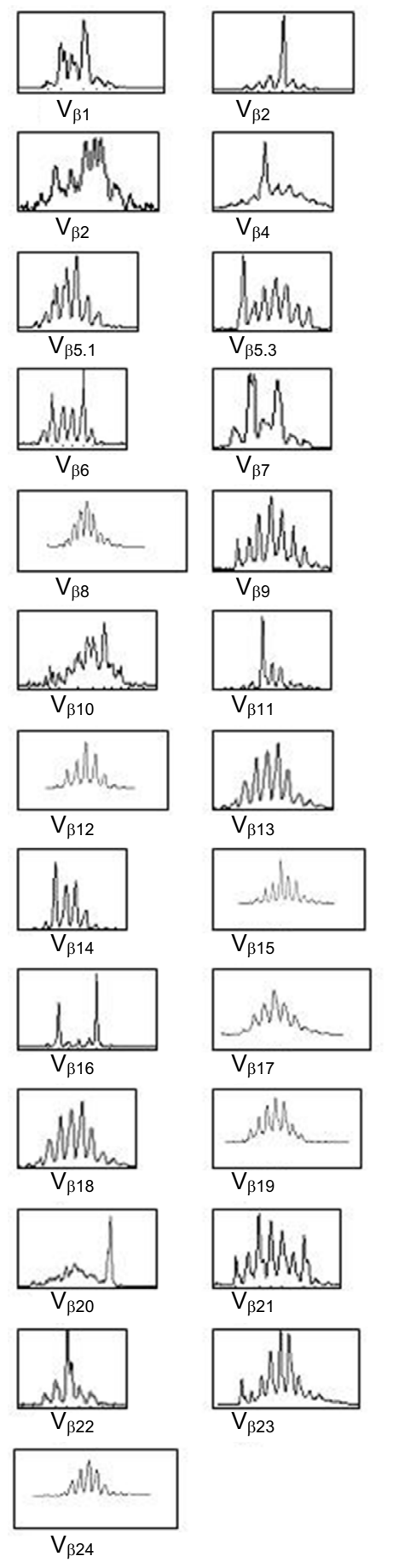

Group HD

Patient 7
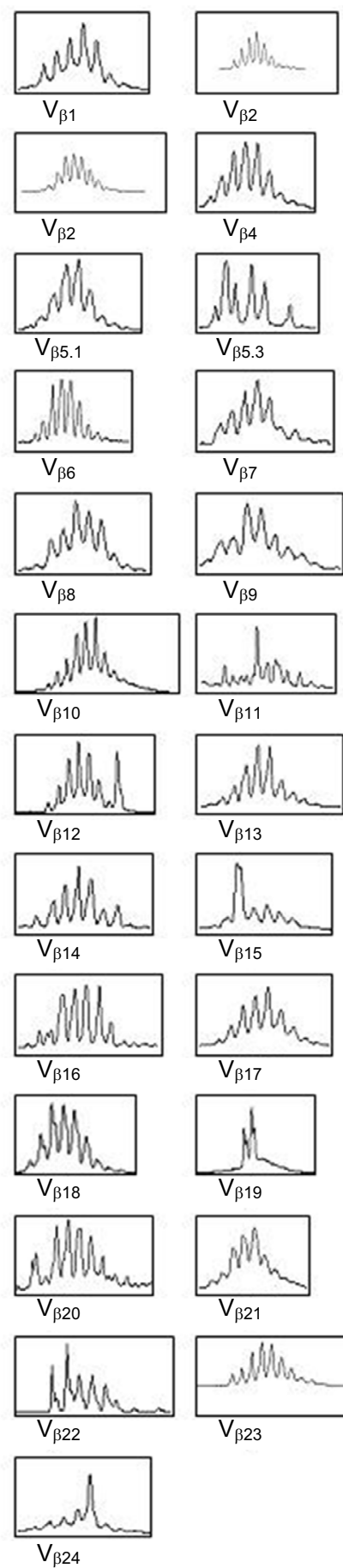

Group C

Patient 12
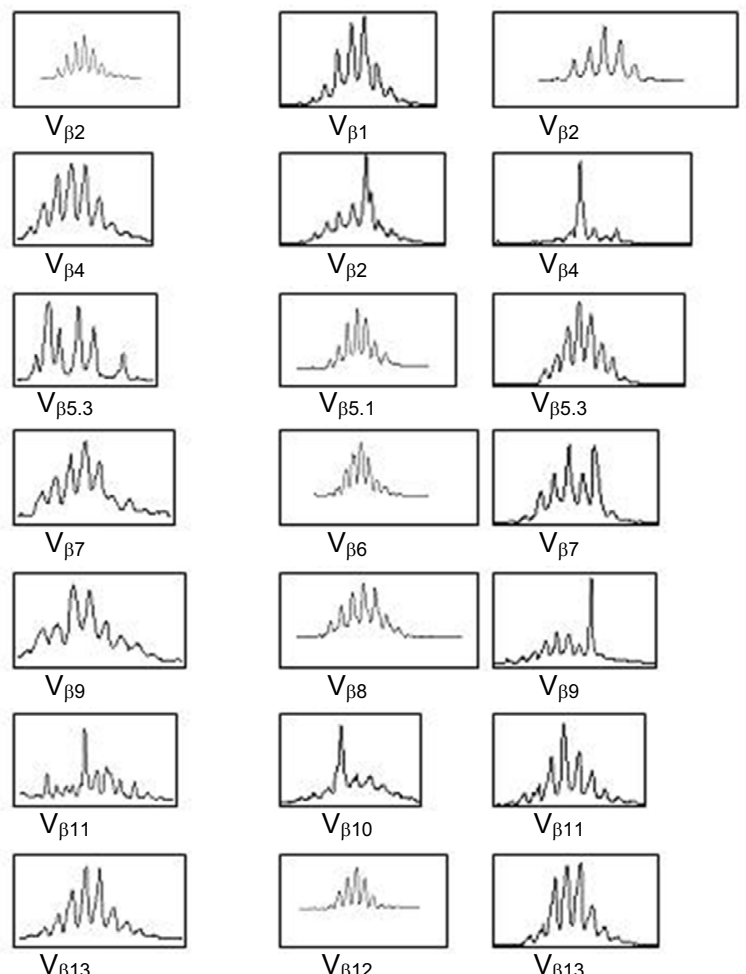

$\frac{{ }_{\mathrm{V}} \text { throm }}{\mathrm{V}_{\beta 10}}$
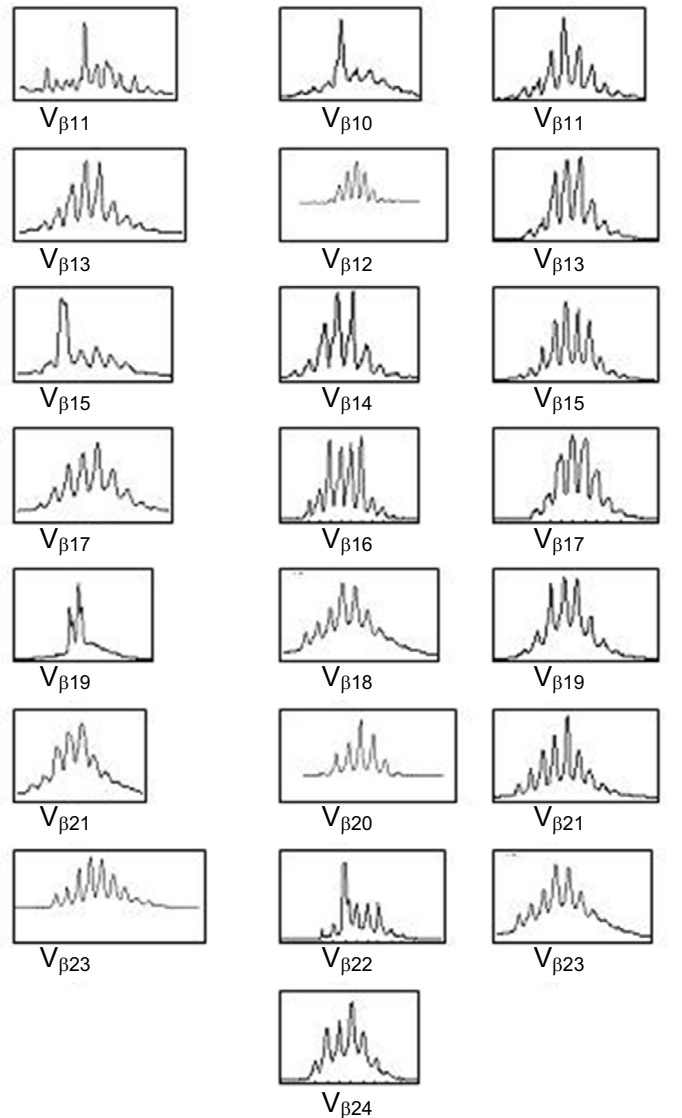

Figure I Complete spectra patterns for patients 2, 7, and 12 .

Notes: Patients 2, 7, and 12 were those with the intermediate number of skewed spectra in group HD-Tx, group HD, and group C, respectively.

Abbreviations: C, control; HD-Tx, hemodialysis-transplant; HD, hemodialysis.

and not characterizing the particular status of the subject (posttransplant, dialysis or healthy), in line with previous data by Barth et al, suggesting that $\mathrm{T}$-cell $\mathrm{V}_{\beta}$-repertoire is restricted and individual in both acute and ongoing chronic allograft rejection before getting to transplant failure. ${ }^{26}$ Thus far, these preliminary data might suggest a possible follow-up approach for renal transplant recipients, considering the changes over time in T-cell CDR3 regions as a reflection of a specific immune status after kidney transplant.

Delayed T-cell recovery and restricted TCR diversity after both hematopoietic stem cell transplantation and solid-organ transplantation appear to increase the risk of opportunistic 
Table 2 Number of skewed bands with median area under the peak (in brackets) for each $\mathrm{V}_{\beta}$ family analyzed in the three groups.

\begin{tabular}{|c|c|c|c|c|}
\hline & HD-Tx $(n=8)$ & HD $(n=7)$ & $C(n=6)$ & $P$ \\
\hline $\mathrm{V}_{\beta 2}$ & $3 / 8(4,928)$ & $0 / 7(9,3 \mid 6)$ & $0 / 6(6,861)$ & NS \\
\hline $\mathrm{V}_{\beta 4}$ & $3 / 8(7,182)$ & $2 / 7(10,367)$ & $0 / 6(11,598)$ & NS \\
\hline $\mathrm{V}_{\beta 5.1}$ & $2 / 8(4,940)$ & $3 / 7(4,885)$ & $0 / 6(5,429)$ & NS \\
\hline $\mathrm{V}_{\beta 5.3}$ & $3 / 8(3,493)$ & $3 / 7(1,465)$ & $0 / 6(2,594)$ & NS \\
\hline $\mathrm{V}_{\beta 7}$ & $4 / 8(8,50 I)$ & $2 / 7(9,850)$ & $0 / 6(17,732)$ & NS \\
\hline $\mathrm{V}_{\beta 9}$ & $2 / 8(4,284)$ & $2 / 7(2,260)$ & $0 / 6(11,509)$ & NS \\
\hline $\mathrm{V}_{\beta 12}$ & I/8 (2,096) & $0 / 7(3,145)$ & $0 / 6$ (719) & NS \\
\hline $\mathrm{V}_{\beta 13}$ & I/8 (I2,303) & $2 / 7(\mid 2,693)$ & $0 / 6(23,654)$ & NS \\
\hline $\mathrm{V}_{\beta 14}$ & $2 / 8(1,935)$ & $1 / 7(25,177)$ & $0 / 6(1,876)$ & NS \\
\hline $\mathrm{V}_{\beta 15}$ & $2 / 8(5,846)$ & $3 / 7(7,575)$ & $0 / 6(2,802)$ & NS \\
\hline $\mathrm{V}_{\beta 16}$ & $3 / 8(3,094)$ & $2 / 7(7,457)$ & $0 / 6(6,777)$ & NS \\
\hline $\mathrm{V}_{\beta 17}^{\mathrm{pol}}$ & $3 / 8(1,586)$ & $\mathrm{I} / 7(3,963)$ & $0 / 6(6,169)$ & NS \\
\hline $\mathrm{V}_{\beta 19}$ & I/8 (II,208) & I/7 $(25,098)$ & $0 / 6(15,592)$ & NS \\
\hline $\mathrm{V}_{\beta 21}$ & I/8 $(4,354)$ & $3 / 7(2,018)$ & $0 / 6(|3,48|)$ & NS \\
\hline $\mathrm{V}_{\beta 23}$ & $3 / 8(10,385)$ & I/7 (I5,294) & $0 / 6(27,75 I)$ & NS \\
\hline $\mathrm{V}_{\beta 24}$ & I/8 (I,6I4) & $3 / 7(1,4 \mid 0)$ & $4 / 6(2,520)$ & NS \\
\hline Total & $35 / 128(27.3 \%)$ & $29 / 112$ (25.9\%) & $4 / 96(4.2 \%)$ & $<0.001$ \\
\hline
\end{tabular}

Notes: Although no differences across the groups emerged when each $V_{\beta}$ family was considered separately (Kruskal-Wallis analysis of variance), significant differences were found in the total number of skewed spectra $\left(\chi^{2}\right.$ test). Individual comparisons through post hoc Mann-Whitney nonparametric tests revealed that healthy subjects had the fewest altered spectra (group HD-Tx vs group $C, P=0.017$; group HD vs group $C, P=0.015$ ), while differences between nonfunctioning kidneytransplant recipients and dialysis patients were not statistically significant (group HD-Tx vs group HD).

Abbreviations: C, control; NS, not significant; HD-Tx, hemodialysis-transplant; $\mathrm{HD}$, hemodialysis.

infections and cancer, with a significant impact on transplant-associated morbidity and mortality. ${ }^{32}$ van Heijst et al investigated clinical parameters potentially able to affect T-cell-repertoire recovery, and found cytomegalovirus or Epstein-Barr virus infections to be associated with lower TCR diversity. ${ }^{33}$ However, our study had the main limitation of considering T-cell-repertoire features in nonfunctioning kidney-transplant recipients vs dialysis patients vs healthy subjects, without examining the outcomes specifically. Although the limited sample size prevents us from drawing firm conclusions about a possible correlation between a given pattern of spectra and a specific clinical condition, the main preliminary finding emerging from our study is the elevated number of skewed spectra in nonfunctioning kidney-transplant recipients under dialysis treatment. Perhaps dialysis treatment alone represents a weaker trigger for clonal expansion of $\mathrm{T}$ cells, even if the difference between nonfunctioning kidneytransplant recipients vs dialysis patients did not meet statistical significance, maybe owing to the small number of subjects.

\section{Conclusion}

Our data indicate that early identification of T-cell clonality renal transplantation might predict a state of immunoactivation against HLAs, thus providing a diagnostic tool not only for acute rejection but also for the identification of cellular clones involved in chronic allograft failure, the leading cause of renal graft loss.

\section{Acknowledgment}

The authors would like to acknowledge Dr Vania Cuna for her essential research assistance.

\section{Disclosure}

The authors report no conflicts of interest in this work.

\section{References}

1. Ghanta M, Jim B. Renal transplantation in advanced chronic kidney disease patients. Med Clin North Am. 2016;100(3):465-476.

2. Sá H, Leal R, Rosa MS. Renal transplant immunology in the last 20 years: a revolution towards graft and patient survival improvement. Int Rev Immunol. Epub 2016 Sep 28.

3. Tanriover B, Jaikaransingh V, MacConmara MP, et al. Acute rejection rates and graft outcomes according to induction regimen among recipients of kidneys from deceased donors treated with tacrolimus and mycophenolate. Clin J Am Soc Nephrol. 2016;11(9):1650-1961.

4. Ville S, Poirier N, Branchereau J, et al. Anti-CD28 antibody and belatacept exert differential effects on mechanisms of renal allograft rejection. J Am Soc Nephrol. 2016;27(12):3577-3588.

5. Solez K, Colvin RB, Racusen LC, et al. Banff '05 meeting report: differential diagnosis of chronic allograft injury and elimination of chronic allograft nephropathy ('CAN'). Am J Transplant. 2007;7(3): 518-526.

6. Scolari MP, Cappuccilli ML, Lanci N, L et al. Predictive factors in chronic allograft nephropathy. Transplant Proc. 2005;37(6):2482-2484.

7. Heaphy EL, Poggio ED, Flechner SM, et al. Risk factors for retransplant kidney recipients: relisting and outcomes from patients' primary transplant. Am J Transplant. 2014;14(6):1356-1367.

8. Panchal H, Muskovich J, Patterson J, Schroder PM, Ortiz J. Expanded criteria donor kidneys for retransplantation: United Network for Organ Sharing update - proceed with caution. Transpl Int. 2015;28(8): 990-999.

9. Gandolfini I, Buzio C, Zanelli P, et al. The Kidney Donor Profile Index (KDPI) of marginal donors allocated by standardized pretransplant donor biopsy assessment: distribution and association with graft outcomes. Am J Transplant. 2014;14(11):2515-2525.

10. Martin-Gandul C, Mueller NJ, Pascual M, Manuel O. The impact of infection on chronic allograft dysfunction and allograft survival after solid organ transplantation. Am J Transplant. 2015;15(12):3024-3040.

11. Fischereder M. Cancer in patients on dialysis and after renal transplantation. Nephrol Dial Transplant. 2008;23(8):2457-2460.

12. Gaston RS. Chronic calcineurin inhibitor nephrotoxicity: reflections on an evolving paradigm. Clin JAm Soc Nephrol. 2009;4(12):2029-2034.

13. Ghanta M, Kozicky M, Jim B. Pathophysiologic and treatment strategies for cardiovascular disease in end-stage renal disease and kidney transplantations. Cardiol Rev. 2015;23(3):109-118

14. Shirali AC, Bia MJ, Denton MD, Magee CC, Sayegh MH. Management of cardiovascular disease in renal transplant recipients. Clin J Am Soc Nephrol. 2008;3(2):491-504.

15. Nakanishi K. Innate and acquired activation pathways in T-cells. Nat Immunol. 2001;2(2):140-142.

16. Pratt JR, Basheer SA, Sacks SH. Local synthesis of complement C3 regulates acute renal transplant rejection. Nat Med.2002;8(6):582-587.

17. Alvarez CM, Opelz G, Garcia LF, Süsal C. Expression of regulatory T-cell-related molecule genes and clinical outcome in kidney transplant recipients. Transplantation. 2009;87(6):857-863.

18. Davis MM, Bjorkman PJ. T-cell antigen receptor genes and T-cell recognition. Nature. 1988;334(6181):395-402.

19. Fields BA, Ober B, Malchiodi EL, et al. Crystal structure of the $\mathrm{V} \alpha$ domain of a T-cell antigen receptor. Science. 1995;270(5243):1821-1824. 
20. Bentley GA, Boulot G, Karjalainen K, Mariuzza RA. Crystal structure of the $\beta$ chain of a T-cell antigen receptor. Science. 1995;267(5206):1984-1987.

21. Gorski J, Yassai M, Zhu X et al. Circulating T-cell repertoire complexity in normal individuals and bone marrow recipients analyzed by CDR3 size spectratyping. J Immunol. 1994;152(10):5109-5119.

22. Vignes C, Chiffoleau E, Douillard P, et al. Anti-TCR-specific DNA vaccination demonstrates a role for a CD8+ T-cell clone in the induction of allograft tolerance by donor-specific blood transfusion. J Immunol. 2000;165(1):96-101.

23. Jiang H, Kashleva $\mathrm{H}, \mathrm{Xu} \mathrm{LX}$, et al. T-cell vaccination induces T-cell receptor V $\beta$-specific Qa-1-restricted regulatory $\mathrm{CD}^{+} \mathrm{T}$-cells. Proc Natl Acad Sci USA. 1998;95(8):4533-4537.

24. Plasilova M, Risitano A, Maciejewski JP. Application of the molecular analysis of the T-cell receptor repertoire in the study of immunemediated hematologic diseases. Hematology. 2003;8(3):173-181.

25. Baron C, McMorrow I, Sachs DH, LeGuern C. Persistence of dominant T-cell clones in accepted solid organ transplants. J Immunol. 2001;167(8):4154-4160.

26. Barth C, Von Menges A, Zanker B et al. Restricted T-cell V $\beta$ repertoire in renal allografts during acute and chronic rejection. Kidney Int. 1996; 50(6):2020-2026.
27. Haarer J. TCR spectratyping in transplantation. Transplantation. 2015; 99(12):2438-2439.

28. Costa AN, Scolari MP, Iannelli S, et al. The presence of posttransplant HLA-specific IgG antibodies detected by enzyme-linked immunosorbent assay correlates with specific rejection pathologies. Transplantation. 1997;63(1):167-169.

29. Ducloux D, Bamoulid J, Courivaud C, et al. Thymic function, antithymocytes globulins, and cancer after renal transplantation. Transpl Immunol. 2011;25(1):56-60.

30. Matsutani T, Ohashi Y, Yoshioka T, et al. Skew in T-cell receptor usage and clonal T-cell expansion in patients with chronic rejection of transplanted kidneys. Transplantation. 2003;75(3):398-407.

31. Morris H, DeWolf S, Robins H, et al. Tracking donor-reactive T-cells: evidence for clonal deletion in tolerant kidney transplant patients. Sci Transl Med. 2015;7(272):272ra10.

32. Lai L, Wang L, Chen $\mathrm{H}$, et al. T cell repertoire following kidney transplantation revealed by high-throughput sequencing. Transpl Immunol. 2016;39:34-45.

33. van Heijst JW, Ceberio I, Lipuma LB, et al. Quantitative assessment of $T$ cell repertoire recovery after hematopoietic stem cell transplantation. Nat Med. 2013;19(3):372-377.
Journal of Inflammation Research

\section{Publish your work in this journal}

The Journal of Inflammation Research is an international, peer-reviewed open access journal that welcomes laboratory and clinical findings on the molecular basis, cell biology and pharmacology of inflammation including original research, reviews, symposium reports, hypothesis formation and commentaries on: acute/chronic inflammation; mediators of

\section{Dovepress}

inflammation; cellular processes; molecular mechanisms; pharmacology and novel anti-inflammatory drugs; clinical conditions involving inflammation. The manuscript management system is completely online and includes a very quick and fair peer-review system. Visit http://www.dove press.com/testimonials.php to read real quotes from published authors. 